Article

\title{
Statistical Damage Model of Altered Granite under Dry-Wet Cycles
}

\author{
Xuxin Chen ${ }^{1,2, *} \mathbb{D}$, Ping $\mathrm{He}^{1,2, *}$, Zhe Qin ${ }^{3}$, Jianye $\mathrm{Li}^{1,2}$ and Yanping Gong ${ }^{1,2}$ \\ 1 School of Civil and Architectural Engineering, Beijing Jiaotong University, Beijing 100044, China; \\ 18125840@bjtu.edu.cn (J.L.); 16121021@bjtu.edu.cn (Y.G.) \\ 2 Tunneling and Underground Engineering Research Center of Ministry of Education, Beijing 100044, China \\ 3 School of Civil Engineering and Architecture, Shandong University of Science and Technology, \\ Qingdao 266590, China; chin@sdust.edu.cn \\ * Correspondence: chenxuxin@bjtu.edu.cn (X.C.); phe@bjtu.edu.cn (P.H.); Tel.: +15753234720 (X.C.); \\ +18301319013 (P.H.)
}

Received: 4 December 2018; Accepted: 25 December 2018; Published: 2 January 2019

\begin{abstract}
This paper presents a new statistical damage constitutive model using symmetric normal distribution. The broken rock microbody obeyed symmetric normal distribution and the equivalent strain principle in damage mechanics. The uniaxial compression tests of samples subjected to dry-wet cycles were performed. The damage model was established using the equivalent strain principle and symmetric normal distribution. The damage variable was defined by the elastic modulus under various dry-wet cycles. Parameters of the damage constitutive model were identified using MATLAB software, and the proposed model is verified to be in good agreement with uniaxial compression test results. Fracturing of the rock microbody is well described by symmetric normal distribution, and the proposed statistical damage constitutive model has good adaptability to the uniaxial compression stress-strain curve.
\end{abstract}

Keywords: dry-wet cycles; symmetric normal distribution; damage variable; equivalent strain principle

\section{Introduction}

Rocks and soils are engineering materials that are widely utilized in geotechnical engineering. Rock heterogeneity and anisotropy makes the investigation of rock constitutive relations complicated and difficult. Micro-cracks and pores are commonly present in rock and represent a kind of initial damage. The expansions of micro-cracks and pores are a common side effect of the excavation of roadways, hydraulic action (water-rock coupling, dry-wet cycles and hydraulic fracturing), or temperature changes (freeze-thaw cycles). The study of rock damage constitutive models is more complicated [1-5]. With the development of continuum damage mechanics, the concept of effective stress and strain equivalent hypothesis provides a mechanical basis for establishing rock damage constitutive models. Parisio F. et al. [6] studied the stability of an excavated area in opalinus clay using an anisotropic plasticity coupled with a damage constitutive model. A new damage constitutive model considering structural healing and decay was established for engineering soft rock [7]. Mortazavi A. et al. [8] presented a realistic damage model with a damage process and plastic flow to analyze the stability of underground tunnels. Cerfontaine B. [9] studied the mechanical response of surrounding rock under cyclic loading in a circular tunnel, and a damage constitutive model based on the boundary surface concept was proposed. A damage constitutive model reflecting rock strain softening characteristics was established to describe rock deformation [10]. Asadollahi P. [11] studied a constitutive model using an empirical equation with normal stress and a modified Joint 
Roughness Coefficient (JRC). Unteregger D. [12] established the constitutive model reflecting the nonlinear behavior of rock on the basis of plasticity theory and damage mechanics. Amorosi A. [13] studied the critical state-based constitutive model for in-situ plate load tests of the mechanical response of pyroclastic rock. Rock is weakened due to the rise and fall of the water level, causing damage to the internal structure of the rock. Dry-wet cycles adversely affect slope stability, so investigations of rock damage constitutive models are critically used to understand rock deformation and failure characteristics. Results can provide a mechanical basis for the slope stability analysis, and a rock damage constitutive model for rock subjected to dry-wet cycles has great significance for slope stability analysis [14-17].

In this paper, the results of rock uniaxial compression test under various dry-wet cycles are studied. According to the theory of damage mechanics, the comprehensive damage variables are defined by coupling the rock hydraulic damage variable and loading damage variable. The adaptability of the damage constitutive model is discussed and evaluated compared to uniaxial compression test results.

\section{Materials and Methods}

\subsection{Research Background}

The open pit is used as a tailings pond. A large number of tailings was stored, and the water used to move the tailing accumulated in the open tailings pit, causing the reservoir water level to rise. At the same time, the clarified water was used as the water source of the concentrator. Therefore, the water level of the tailings pond changes cyclically varies during a certain time period. In order to observe the rise and fall of the water level, a sonic water level detector was set (Figure 1).

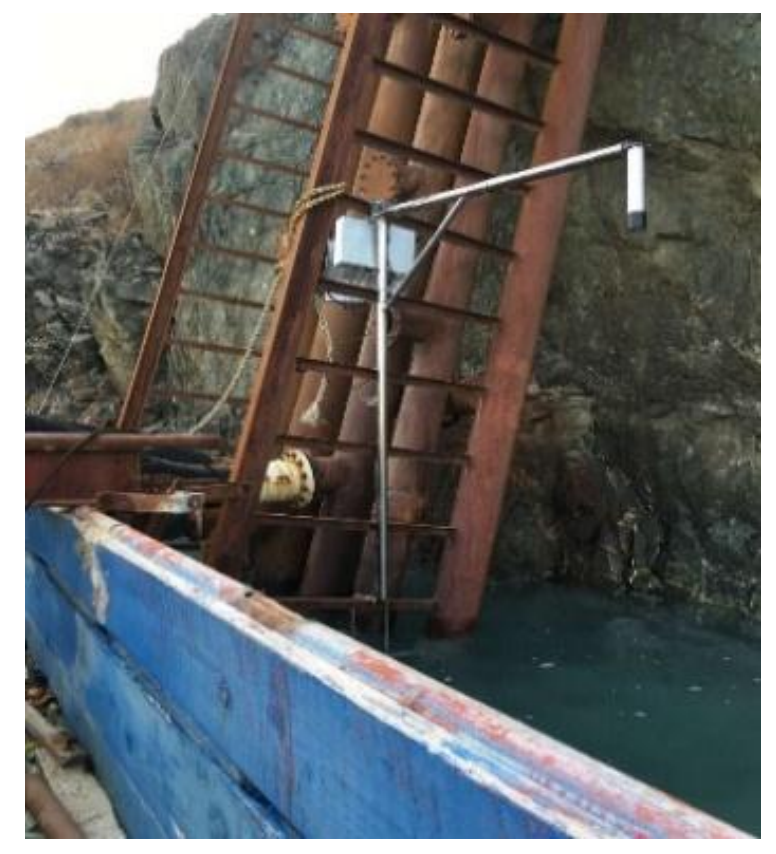

Figure 1. The sonic water level detector.

From March 2016 to October 2018, the water level has varied significantly (Figure 2). The water level initially increased, then decreased. The slope rocks have been experiencing dry-wet cycles for a long time due to the cyclical rise and fall of water level in the open pit. This leads to a decrease in rock strength and increases the probability of a landslide. Therefore, it is of great significance to study the rock damage constitutive model under the action of dry-wet cycles, especially focusing on rock deformation and failure mechanisms from the perspective of damage mechanics. 


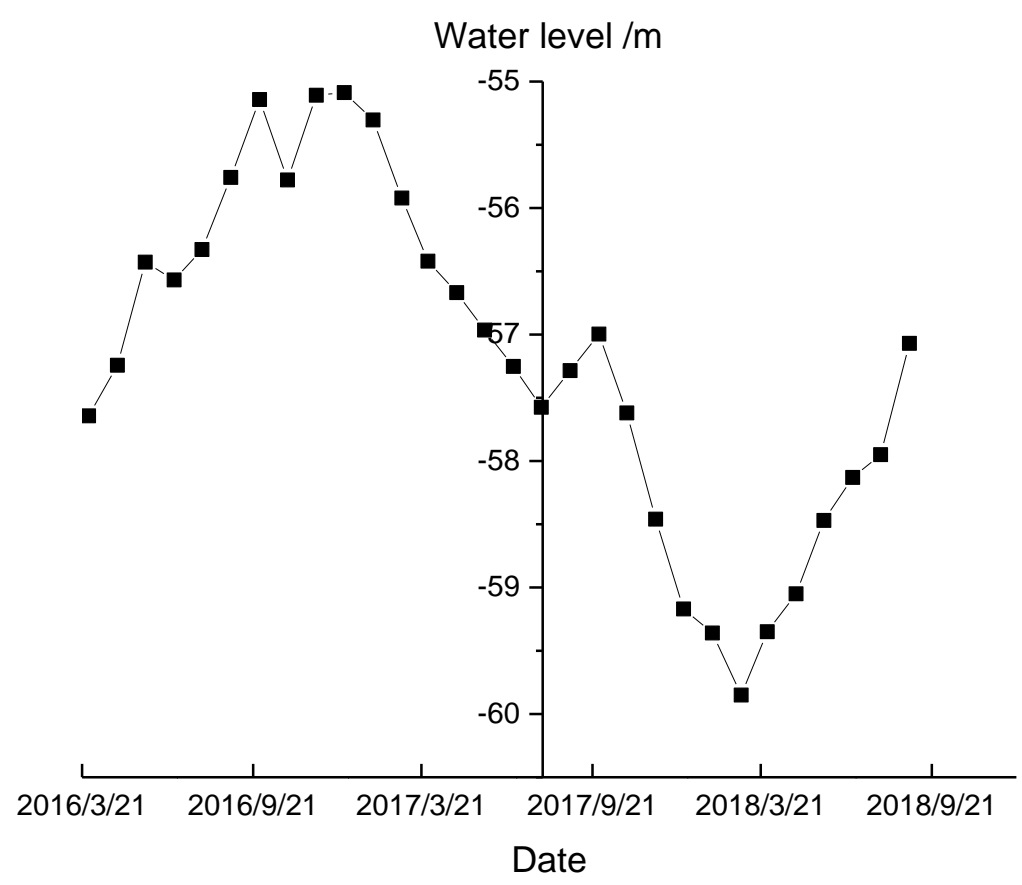

Figure 2. Changes of water level though time.

\subsection{Sample Tested}

The rock samples tested were taken from the slope of open pit in San Shandao deposit [16]. According to the results of electron probe (Figure 3), the main compositions altered granite are $\mathrm{SiO}_{2}$ and $\mathrm{K}_{2} \mathrm{O} \cdot \mathrm{Al}_{2} \mathrm{O}_{3} \cdot 6 \mathrm{SiO}_{2}$.

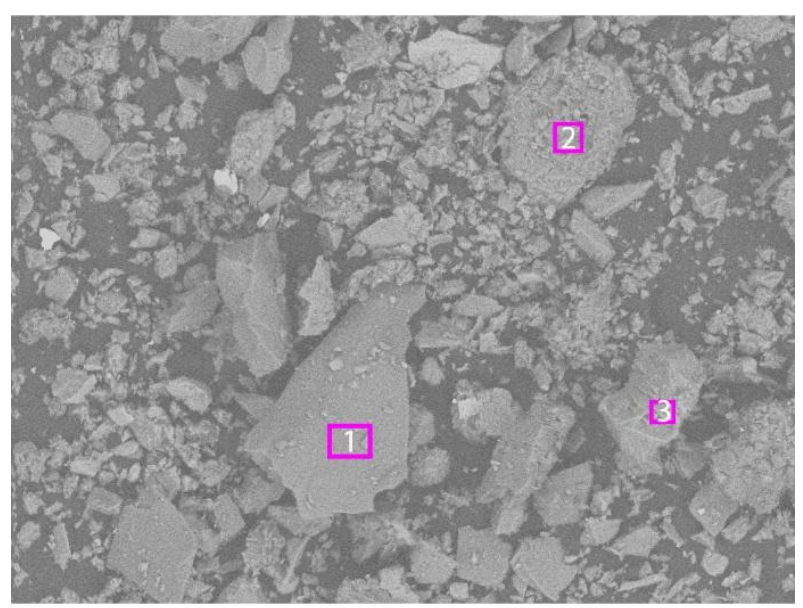

(a)

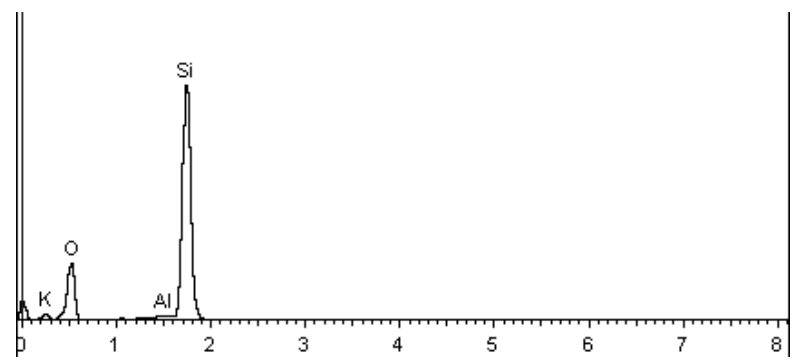

(b)

Figure 3. Cont. 


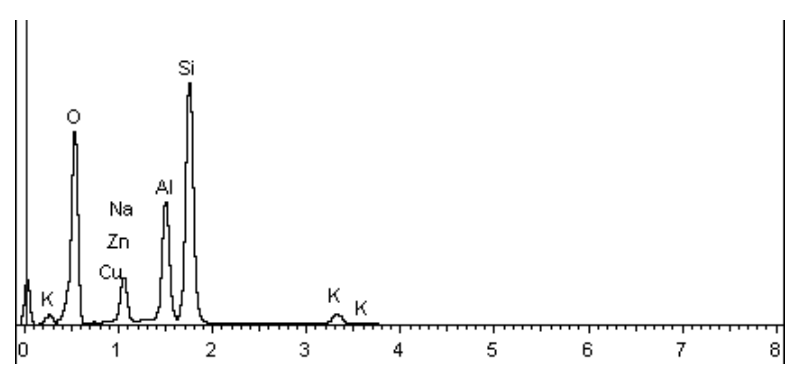

(c)

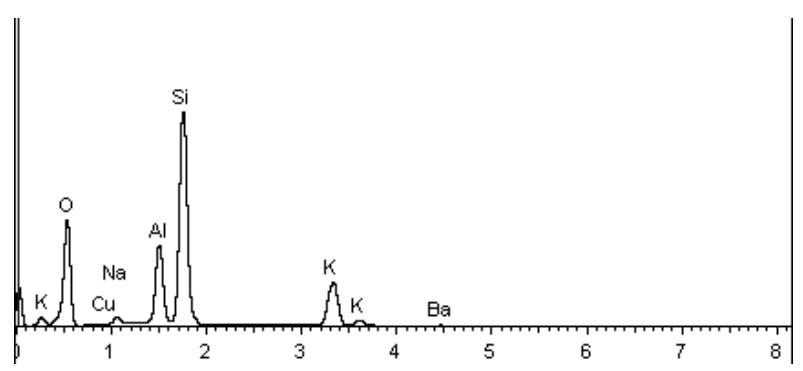

(d)

Figure 3. (a) Results of electron probe; (b) Element recognition of position 1; (c) Element recognition of position 2; (d) Element recognition of position 3.

Samples were symmetrical cylinders that were $50 \mathrm{~mm}$ in diameter and $100 \mathrm{~mm}$ in length. The samples were obtained through core drilling and sawing (Figure 4).

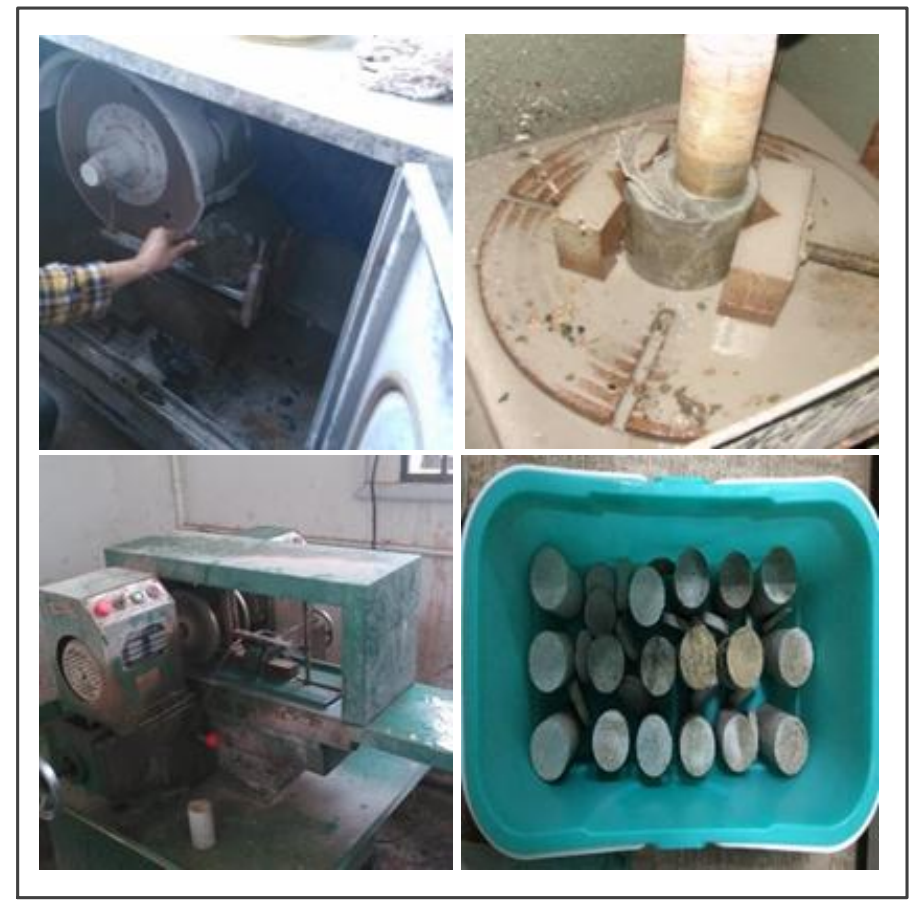

Figure 4. Images showing the preparation of rock samples.

\subsection{Test of Dry-Wet Cycles}

The influence of water level fluctuation in the tailings reservoir was simulated to study the changing of rock mechanical properties. Rock specimens were subjected to the dry-wet cycles test. 
The time which the rock reaches saturation was determined by rock moisture testing. Rock samples were immersed in a neutral solution, at standard atmospheric pressure. According to the results of moisture content tests $[16,17]$, a drying and wetting cycle consisted of freely submerging the specimen in water until it was saturated $(24 \mathrm{~h})$, then placing it into a $105^{\circ} \mathrm{C}$ oven for $12 \mathrm{~h}$, and then cooling it to room temperature.

Uniaxial compression tests were performed after a certain number of dry-wet cycles $(0,5,15,20$, 30, 60). Four samples were prepared for each series of dry-wet cycles, and one of the rock specimens was used as a spare rock sample.

\subsection{Results of Uniaxial Compression Test}

The uniaxial compression tests were performed under various dry-wet cycles, including rock after 0 dry-wet cycles, rock after 5 dry-wet cycles, rock after 15 dry-wet cycles, rock after 20 dry-wet cycles, rock after 30 dry-wet cycles, rock after 60 dry-wet cycles. A SHIMADZU compression tester was used to obtain the compression stress-strain curve of the rock under dry-wet cycles (Figure 5).

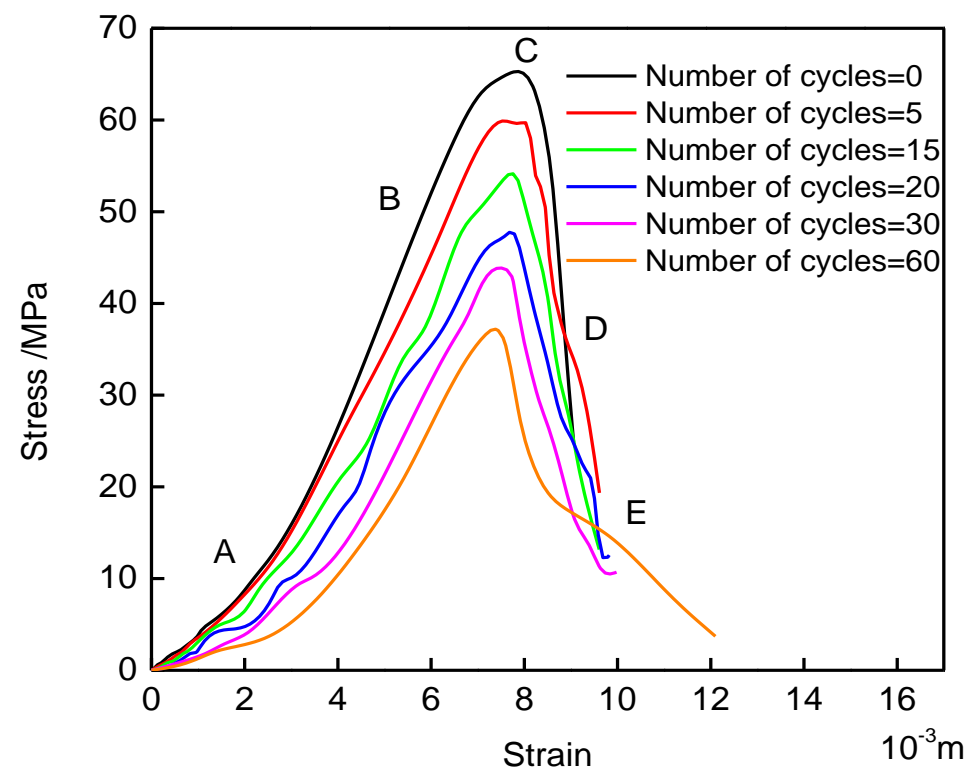

Figure 5. Stress-strain curve for rock samples subjected to various number of wet-dry cycles.

According to Figure 5, the uniaxial compression stress-strain curve shows five distinct stages, including internal defect closure stage $(\mathrm{OA})$, linear elastic deformation stage $(\mathrm{AB})$, unsteady rupture stage (BC), plastic yield stage (CD) and strain softening stage (DE). The peak strength of the rock gradually decreases as the number of cycles increases.

\section{Damage Variables under Dry-Wet Cycles}

Damage mechanics describes the mechanical behavior of engineering materials. This paper proposes a new statistical damage constitutive model considering the number of dry-wet cycles and the loading process. A comprehensive damage variable is defined coupling rock hydraulic damage variable and loading damage variable. 


\subsection{Hydraulic Damage Variable $\left(D_{w}\right)$}

This paper presents the hydraulic damage variable using an elastic modulus. The elastic modulus of samples under various dry-wet cycles decreased with an increasing number of cycles. Meanwhile, the damage variable was defined by elastic modulus [18]. The $D_{w}$ was defined as Equation (1).

$$
D_{w}=1-\frac{E_{N}}{E_{0}}
$$

In the Equation (1), $D_{w}$ is the hydraulic damage variable, $E_{N}$ is the elastic modulus after $N$ number of dry-wet cycles and $E_{0}$ is the elastic modulus after a 0 number of dry-wet cycles.

\subsection{Loading Damage Variable $\left(D_{m}\right)$}

A normal distribution is also called a Gaussian distribution, which are the most important probability distributions. The form of a normal distribution is simple and can be used to describe the variation of rock micro-body strength. In general, random variables tend to follow a Gaussian distribution. However, due to the complexity of external conditions, the normal distribution is extended into multidimensional space. According to the central limit theorem, if a large number of independent random variables are properly normalized, they will converge to a Normal (Gaussian) distribution. Due to the existence of defects, such as pores and fissures inside the rock, and the irregularity of the defects, the distribution of rock micro-body strength tends to follow the normal distribution $[19,20]$.

The $N$ dimensional random variable $X=\left(X_{1}, X_{2}, \ldots, X_{n}\right)$ obeyed the normal distribution with parameter of $a$ and $B$, and its probability density function is given by Equation (2) [21,22].

$$
p(x)=f\left(x_{1}, x_{2}, \ldots, x_{n}\right)=\frac{1}{(2 \pi)^{n / 2}(\operatorname{det} B)^{1 / 2}} \exp \left\{-\frac{1}{2}(X-a)^{T} B^{-1}(X-a)\right\}
$$

where $B$ is a positive definite symmetric matrix (Equation (6)), $\operatorname{det}(B)$ is its determinant, and $B^{-1}$ is its inverse matrix. $a$ presents any real-valued column vector. a lowercase letter was used to record the vector, and a uppercase letter was used to record the matrix, as shown in Equations (3)-(6) [21,22].

$$
\begin{gathered}
a=\left(a_{1}, a_{2}, \ldots, a_{n}\right)^{T} \\
X=\left(x_{1}, x_{2}, \ldots, x_{n}\right)^{T} \\
X-a=\left(x_{1}-a_{1}, x_{1}-a_{2}, \ldots, x_{n}-a_{n}\right)^{T} \\
B=\left[\begin{array}{cccc}
b_{11} & b_{12} & \ldots & b_{1 n} \\
b_{21} & b_{22} & \ldots & b_{2 n} \\
\vdots & \vdots & \ddots & \vdots \\
b_{n 1} & b_{n 1} & \ldots & b_{n n}
\end{array}\right]
\end{gathered}
$$

At present, the most commonly used one-dimensional normal distribution is

$$
f(x)=\frac{1}{\zeta \sqrt{2 \pi}} \exp \left[-\frac{(x-\mu)^{2}}{2 \zeta^{2}}\right]
$$

where $\mu$ is a mathematical expectation, and $\zeta$ is variance. According to the principle of normal distribution.

Normal distribution curves have absolute symmetry (Figure 6). The $\mu$ affects the position of the axis, and is called the mathematical expectation, indicating the peak of the symmetric normal distribution. The axis of symmetry is $x=\mu$ and a change in $\mu$ does not change the shape of the curve. 
The parameter $\zeta$ is the variance, which mainly affects the fatness and thinness of the symmetric normal distribution curves.

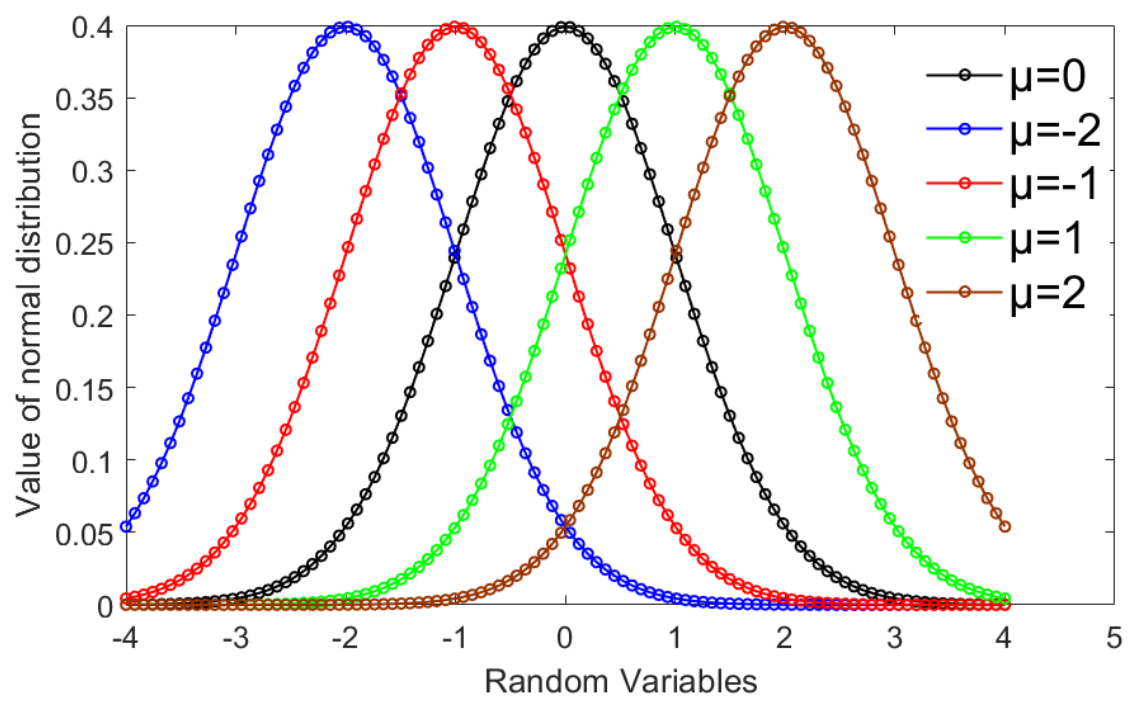

(a)

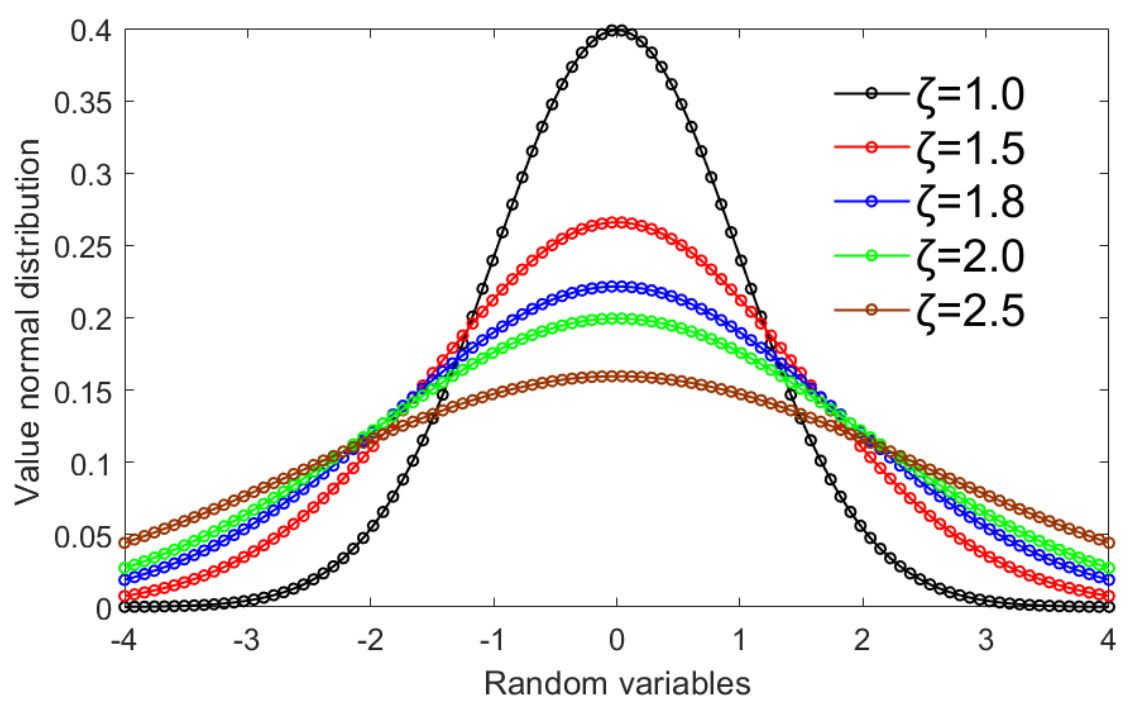

(b)

Figure 6. (a) One-dimensional normal distribution with different $\mu$, (b) One-dimensional normal distribution with different $\zeta$.

The rock is damaged by external loading during the uniaxial compression loading process. Generally, the rock can be divided into several micro-element bodies. For the mechanical damage caused by the dry-wet cycles, the probability density of rock micro-body damage follows a symmetric normal distribution law, and the micro-body damage probability density, as shown in Equation (8).

Based on the above analysis, the mechanical damage variable $D_{m}$ can be obtained by defining the ratio of the number of micro-members broken to the total number of micro-members, as shown in Equation (8):

$$
D_{m}=\frac{N_{f}}{N}=\frac{\int_{0}^{\varepsilon} N \cdot f(x) d x}{N}=\frac{1}{\zeta \sqrt{2 \pi}} \int_{0}^{\varepsilon} \exp \left[-\frac{(x-\mu)^{2}}{2 \zeta^{2}}\right] d x
$$

where $N_{f}$ is the number of damaged micro-elements; $N$ is the total number of micro-elements; $\varepsilon$ is rock strain. 


\subsection{Comprehensive Damage Variable (D)}

Considering the combined damage of dry-wet cycles and mechanical loading on rock strength, the hydraulic damage variable $\left(D_{w}\right)$ and loading damage variable $\left(D_{m}\right)$ were defined respectively, as shown in Equations (1) and (8). The comprehensive damage variable (D) was defined in Equation (11).

$$
\begin{gathered}
1-D=\left(1-D_{w}\right)\left(1-D_{m}\right) \\
D=D_{w}+D_{m}-D_{w} \cdot D_{m} \\
D=\left(1-\frac{E(N)}{E_{0}}\right) \quad+\frac{1}{\sqrt{2 \pi \zeta}} \int_{0}^{\varepsilon} \exp \left[-\frac{(x-\mu)^{2}}{2 \zeta^{2}}\right] d x \\
-\left(\left(1-\frac{E(N)}{E_{0}}\right) \cdot\left(\frac{1}{\sqrt{2 \pi \zeta}} \int_{0}^{\varepsilon} \exp \left[-\frac{(x-\mu)^{2}}{2 \zeta^{2}}\right] d x\right)\right)
\end{gathered}
$$

\section{Damage Constitutive Model under Dry-Wet Cycles}

\subsection{Damage Constitutive Model}

According to the theory of rock strain mechanical strain equivalence, the constitutive relationship of rock before and after damage has the same form, the difference is the between the Cauchy stress and Effective stress. Therefore, the rock damage constitutive equation is shown in Equation (12) [23,24]:

$$
\varepsilon=\widetilde{\sigma} / E=\frac{\sigma}{((1-D) E)}
$$

where $\varepsilon$ is rock strain, $\sigma$ is rock nominal stress, $\widetilde{\sigma}$ is rock effective stress, $E$ is original elastic modulus, and $D$ is the comprehensive damage variable.

Therefore, the damage constitutive model under dry-wet cycles in uniaxial loading conditions is given by Equation (13):

$$
\sigma=E(N) \cdot \lambda \cdot(1-D) \cdot \varepsilon=E_{0} \cdot\left(1-D_{w}\right)\left(1-D_{m}\right)
$$

where $\sigma, \varepsilon$ is the stress and strain of the rock, $\lambda$ is a constant using to describe the defects in rock. $D_{w}$ is the hydraulic damage variable, $D_{m}$ is the loading damage variable, and $D$ is the comprehensive damage variable of the rock.

The damage constitutive model of rock under the action of dry-wet cycles was established by combining Equations (1), (8), and (11), as shown in Equation (14)

$$
\sigma=E(N) \cdot \lambda \cdot\left(1-\frac{1}{\zeta \sqrt{2 \pi}} \int_{0}^{\varepsilon} \exp \left[-\frac{(x-\mu)^{2}}{2 \zeta^{2}}\right] d x\right) \cdot \varepsilon
$$

\subsection{Comparison of Damage Model and Test Results}

Parameters of the damage constitutive model under different dry-wet cycles were obtained according to the fitting results using Matlab software (Table 1).

Table 1. Fitting parameter values for the damage constitutive model.

\begin{tabular}{cccc}
\hline Number of Cycles & $\boldsymbol{\mu}$ & $\boldsymbol{\zeta}$ & $\boldsymbol{R}^{\mathbf{2}}$ \\
\hline 0 & 8.653 & 0.394 & 0.9758 \\
5 & 8.667 & 0.614 & 0.9787 \\
15 & 8.592 & 0.505 & 0.9622 \\
20 & 8.637 & 0.618 & 0.9404 \\
30 & 8.297 & 0.577 & 0.9132 \\
60 & 8.140 & 0.589 & 0.9163 \\
\hline
\end{tabular}


The constant was used to describe the defects in rock $\lambda=2$. Parameters in the rock damage constitutive model were obtained using the uniaxial compression test results. According to Table 1 and Figure $7, \mu$ decreased with an increasing number of cycles, and $\zeta$ increased with an increasing number of cycles.

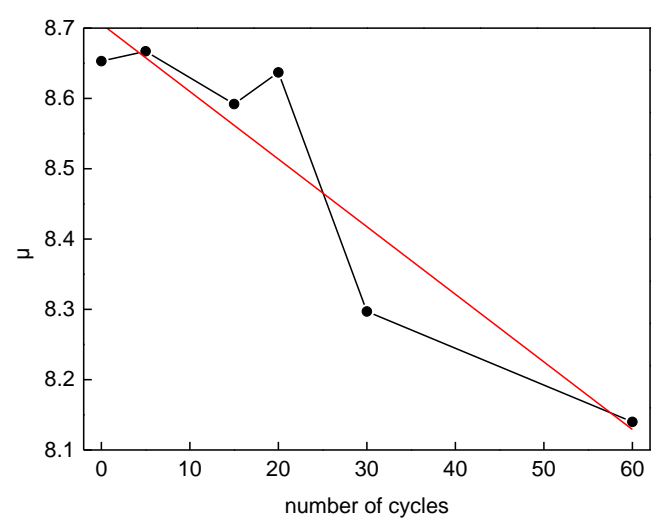

(a)

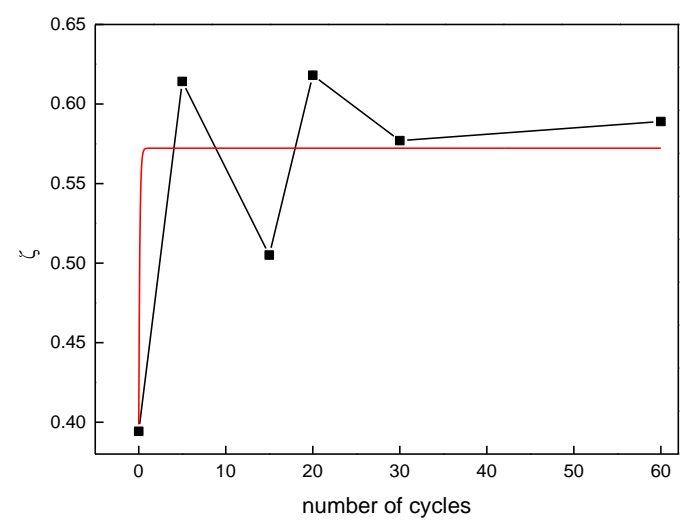

(b)

Figure 7. (a) change of the parameter of $\zeta ;(\mathbf{b})$ change of the parameter of $\mu$.

The damage constitutive model and test results are compared, and the results are shown in Figure 8.

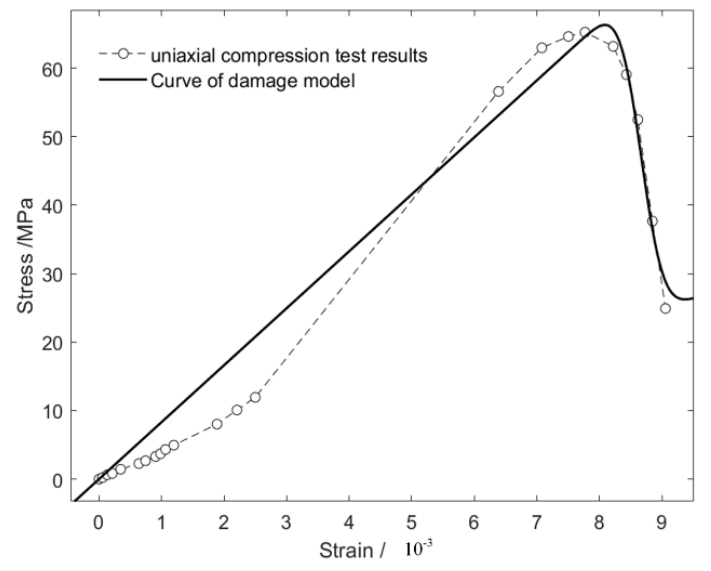

(a)

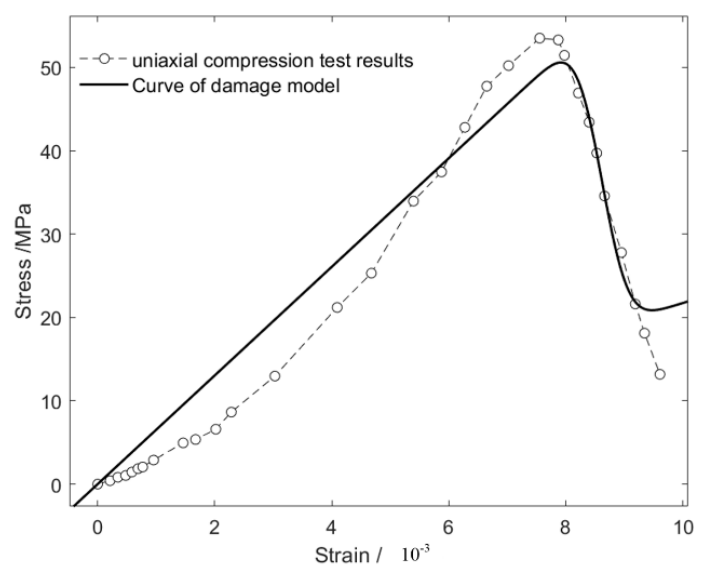

(c)

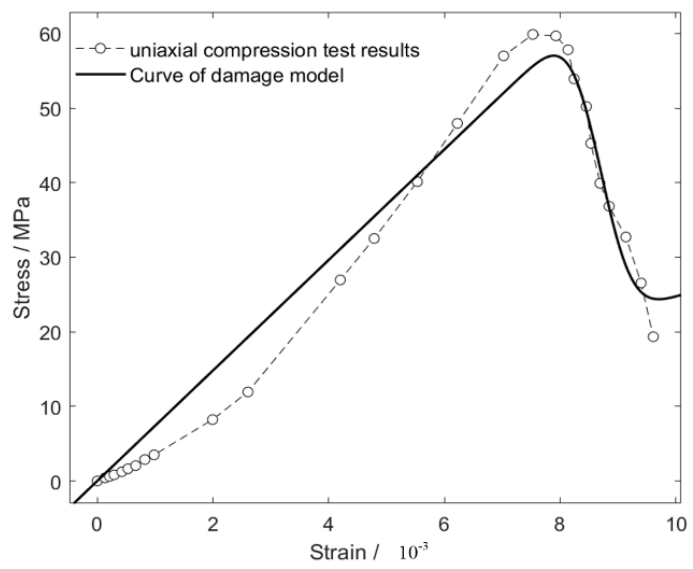

(b)

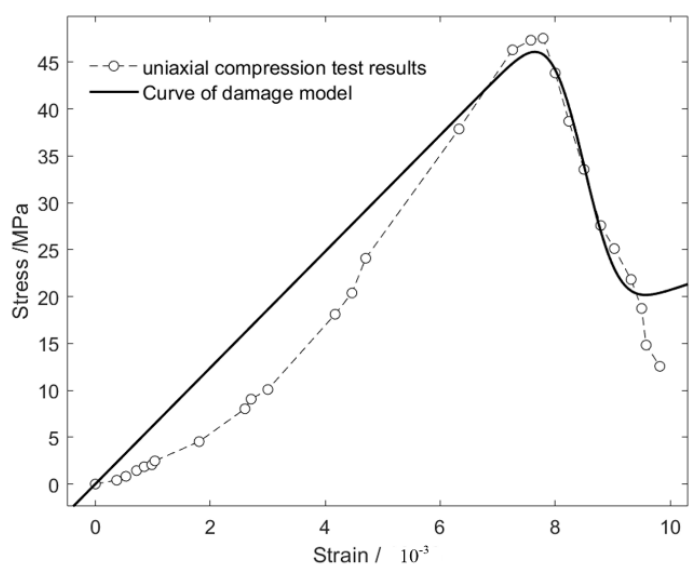

(d)

Figure 8. Cont. 


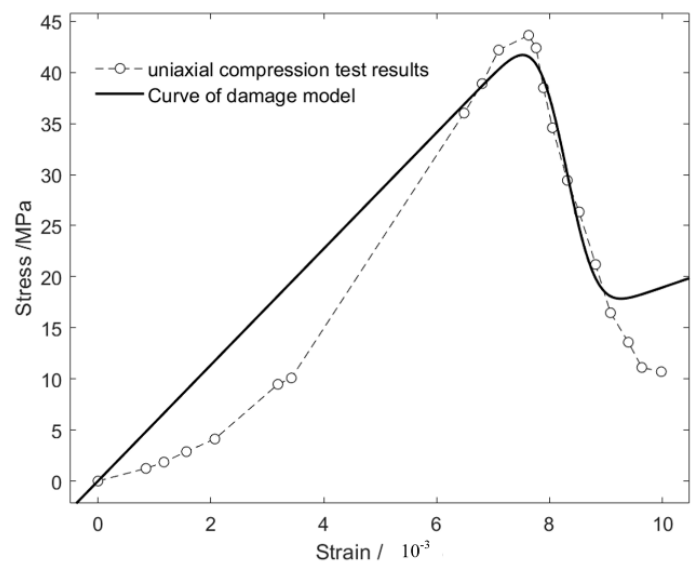

(e)

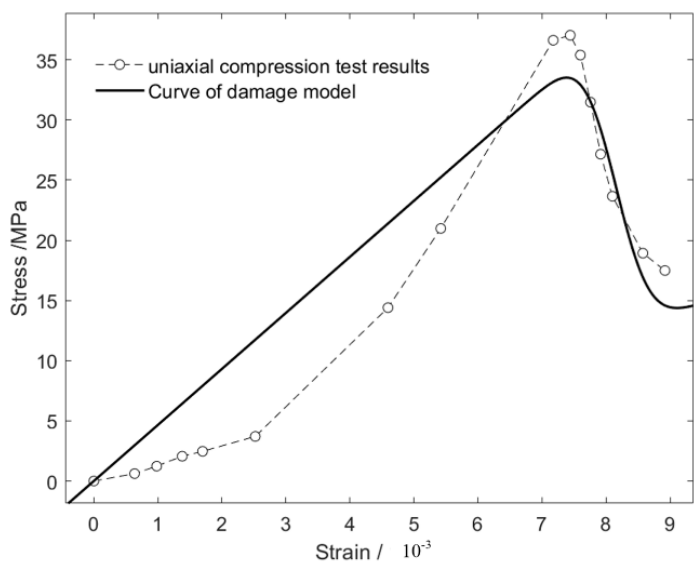

(f)

Figure 8. (a) Comparison of the damage model and test results after 0 dry-wet cycle; (b) Comparison of damage model and test results after 5 dry-wet cycles; (c) Comparison of damage model and test results after 15 dry-wet cycles; (d) Comparison of damage model and test results after 20 dry-wet cycles; (e) Comparison of damage model and test results after 30 dry-wet cycles; (f) Comparison of damage model and test results after 60 dry-wet cycles.

Aiming at the construction of rock damage constitutive model of dry-wet cycles, this paper considers the mechanical damage caused by dry-wet cycles and uniaxial loading, defines the comprehensively damage variable of rock. The adaptability of the constitutive model to the rock stress-strain curve was analyzed. Results show that the comprehensive damage variable considering rock hydraulic damage and mechanical damage can describe the rock damage under dry-wet cycles. The damage constitutive model has good adaptability to the rock stress-strain curve.

\subsection{Discussion}

According to Figure 8 and Table 1 , the fitting variance is greater than 0.910 , and the fitting accuracy meets the needs of engineering stability analysis. The damage constitutive model has strong adaptability to the rock stress-strain curve. The damage constitutive model can provide a mechanical basis for engineering stability analysis.

The rock stress-strain behavior before and after the peak damage can be better described using the damage constitutive model, but it has a poor adaptability to the deformation characteristics in the elastic deformation stage, which is related to the closure and development of the internal pores and fissures of the rock. Therefore, the mesoscopic-damage constitutive model of rock should be further studied.

\section{Conclusions}

In this paper, a damage constitutive model of rock subjected to dry-wet cycles is studied, focusing on the definition of the damage variable. The main conclusions are as follows:

According to the deformation and failure characteristics of rock under the action of dry-wet cycles, a rock damage constitutive model was established. This model was based on the principle of damage mechanics and the symmetric normal distribution theory. The parameters of the damage constitutive model under dry-wet cycles were identified. The fitting variance is greater than 0.910 , and the fitting accuracy meets the needs of engineering stability analysis. The rock damage constitutive model and uniaxial compression test results were compared, and results show that the damage constitutive model has good adaptability to rock stress-strain curves. 
Author Contributions: X.C. and Z.Q. designed and directed the project. X.C. processed the experimental data, performed the analysis, drafted the manuscript and designed the figures. P.H. provided critical revision and acquisition of the financial support for the project leading to this publication; Y.G. and J.L. processed the experimental data. All authors contributed to the final version of the manuscript.

Funding: This research was funded by Shandong Provincial Natural Science Foundation grant number NO. ZR2017BEE014 and Scientific Research Foundation of Shandong University of Science and Technology for Recruited Talents grant number 2017RCJJ050.

Acknowledgments: This paper is supported by Project NO. ZR2017BEE014 of the Shandong Provincial Natural Science Foundation and Scientific Research Foundation of Shandong University of Science and Technology for Recruited Talents (2017RCJJ050). The financial aids are gratefully acknowledged.

Conflicts of Interest: The authors declare that there are no conflicts of interest regarding the publication of this paper.

\section{References}

1. Minardi, A.; Ferrari, A.; Ewy, R. Nonlinear Elastic Response of Partially Saturated Gas Shales in Uniaxial Compression. Rock Mech. Rock Eng. 2018, 3, 1-12. [CrossRef]

2. Wang, Z.L.; Shi, H.; Wang, J.G. Mechanical Behavior and Damage Constitutive Model of Granite Under Coupling of Temperature and Dynamic Loading. Rock Mech. Rock Eng. 2018, 15, 1-16. [CrossRef]

3. Liu, L.; Xu, W.Y.; Zhao, L.Y. An Experimental and Numerical Investigation of the Mechanical Behavior of Granite Gneiss Under Compression. Rock Mech. Rock Eng. 2016, 50, 1-8. [CrossRef]

4. Berto, L.; Saetta, A.; Talledo, D. Constitutive model of concrete damaged by freeze-thaw action for evaluation of structural performance of RC elements. Constr. Build. Mater. 2015, 98, 559-569. [CrossRef]

5. Raude, S.; Laigle, F.; Giot, R. A unified thermoplastic/viscoplastic constitutive model for geomaterials. Acta Geotech. 2016, 11, 849-869. [CrossRef]

6. Parisio, F.; Vilarrasa, V.; Laloui, L. Hydro-mechanical Modeling of Tunnel Excavation in Anisotropic Shale with Coupled Damage-Plasticity and Micro-dilatant Regularization. Rock Mech. Rock Eng. 2018, 51, 3819-3833. [CrossRef]

7. Kikumoto, M.; Nguyen, V.P.Q.; Yasuhara, H. Constitutive model for soft rocks considering structural healing and decay. Comput. Geotech. 2017, 91, 93-103. [CrossRef]

8. Mortazavi, A.; Molladavoodi, H. A numerical investigation of brittle rock damage model in deep underground openings. Eng. Fract. Mech. 2012, 90, 101-120. [CrossRef]

9. Cerfontaine, B.; Charlier, R.; Collin, F. Validation of a New Elastoplastic Constitutive Model Dedicated to the Cyclic Behavior of Brittle Rock Materials. Rock Mech. Rock Eng. 2017, 50, 2677-2694. [CrossRef]

10. Li, X.; Cao, W.G.; Su, Y.H. A statistical damage constitutive model for softening behavior of rocks. Eng. Geotech. 2012, 113-114, 1-17. [CrossRef]

11. Asadollahi, P.; Tonon, F. Constitutive model for rock fractures: Revisiting Barton's empirical model. Eng. Geotech. 2010, 113, 11-32. [CrossRef]

12. Unteregger, D.; Fuchs, B.; Hofstetter, G. A damage plasticity model for different types of intact rock. Int. J. Rock Mech. Min. Sci. 2015, 80, 402-411. [CrossRef]

13. Amorosi, A.; Aversa, S.; Boldini, D. Application of a new constitutive model to the analysis of plate load tests in a pyroclastic rock. Int. J. Rock Mech. Min. Sci. 2015, 78, 271-282. [CrossRef]

14. Özbek, A. Investigation of the effects of wetting-drying and freezing-thawing cycles on some physical and mechanical properties of selected ignimbrites. Bull. Eng. Geol. Environ. 2014, 73, 595-609. [CrossRef]

15. Khanlari, G.; Abdilor, Y. Influence of dry-wet, freeze-thaw, and heat-cool cycles on the physical and mechanical properties of Upper Red sandstones in central Iran. Bull. Eng. Geol. Environ. 2015, 74, 1287-1300. [CrossRef]

16. Qin, Z.; Chen, X.X.; Fu, H.L. Damage Features of Altered Rock Subjected to Drying-Wetting Cycles. Adv. Civ. Eng. 2018, 1, 1-10. [CrossRef]

17. Chen, X.X.; Gong, Y.P. Features of Shear Strength Parameters Reflecting Damage to Rock Caused by Water Invasion-Loss Cycles. Geotech. Geol. Eng. 2018. [CrossRef]

18. Krajcinovic, D. Damage mechanics. Mech. Mater 1989, 8, 117-197. [CrossRef]

19. Wu, Y.; Wang, W.H.; Yang, W.Q. Probability Theory and Mathematical Statistics; Higher Education Press: Beijing, China, 2016. 
20. Yan, C.F.; Xu, J. Probability Model of Rock Mass Strength Criterion and Its Application; Chongqing University Press: Chongqing, China, 1999.

21. Cao, W.G.; Li, X.; Zhao, H. Damage constitutive model for strain-softening rock based on normal distribution and its parameter determination. J. Cent. South Univ. Technol. 2007, 14, 719-724. [CrossRef]

22. Paisley, J.; Wang, C.; Blei, D.M. The Discrete Infinite Logistic Normal Distribution. Bayesian Anal. 2012, 15, 74-82. [CrossRef]

23. Bian, K.; Liu, J.; Zhang, W. Mechanical Behavior and Damage Constitutive Model of Rock Subjected to Water-Weakening Effect and Uniaxial Loading. Rock Mech. Rock Eng. 2018. [CrossRef]

24. Grgic, D. Constitutive modelling of the elastic-plastic, viscoplastic and damage behaviour of hard porous rocks within the unified theory of inelastic flow. Acta Geotech. 2016, 11, 95-126. [CrossRef]

2019 by the authors. Licensee MDPI, Basel, Switzerland. This article is an open access article distributed under the terms and conditions of the Creative Commons Attribution (CC BY) license (http:// creativecommons.org/licenses/by/4.0/). 